\title{
Pretreatment PET in breast cancer: is there a role?
}

\author{
Sue Chua $\cdot$ Ashley M. Groves
}

Published online: 20 September 2012

(C) Springer-Verlag 2012

Breast carcinoma shows greater heterogeneity than the vast majority of adenocarcinomas and carries a highly variable prognosis dependent on a wide range of factors, including tumour size and stage, histological subtype, grade, hormone receptor status and a growing range of molecular abnormalities. Accurate preoperative prognostication is highly important in selecting the most appropriate individualized therapy for a particular patient, and considerable interest is now being focused on noninvasive imaging as a means to achieve this. The ability of ${ }^{18} \mathrm{~F}-\mathrm{FDG}$ PET/CT to combine functional and anatomical data has contributed enormously to oncology [1], and in particular to the emerging field of personalized medicine [2], but it has not yet found a routine role in the preoperative assessment of breast cancer. We ask here whether this situation is likely to change.

${ }^{18}$ F-FDG PET already plays an important part in the work-up and monitoring of metastatic or recurrent breast cancer [3], where it is especially valuable in restaging. Its ability to provide an early and accurate assessment of response to therapy has also made a substantial contribution to the management of patients with both locally advanced and metastatic disease [4]. It may also have a role in primary staging for distant disease in selected high-risk patients, such as those with large (over $3 \mathrm{~cm}$ in diameter) tumours, where in one prospective study it achieved excellent sensitivity and specificity in the detection of distant metastases (100\% and $98 \%$, respectively) and led to a change in the initial staging in $42 \%$ of patients [5]. A further series

S. Chua

The Royal Marsden NHS Foundation Trust,

Sutton, UK

\section{A. M. Groves $(\square)$}

Institute of Nuclear Medicine, University College London,

5th floor, Tower, 235 Euston Road,

London NW1 2BU, UK

e-mail: ashleygroves@nhs.net suggested that preoperative PET/CT can have a significant impact on initial staging and on clinical management in patients with early-stage breast cancer with tumours larger than $2 \mathrm{~cm} \mathrm{[6].} \mathrm{In} \mathrm{addition} \mathrm{to} \mathrm{detecting} \mathrm{distant} \mathrm{metastases} \mathrm{in}$ $15 \%$ of these patients, PET showed unsuspected synchronous primary carcinomas at other sites in $2 \%$ of patients. The findings of another study on early breast tumours were also promising [7]. PET/CT had the potential to impact management in approximately $16 \%$ of patients.

Whether PET has a place in routine preoperative assessment is still unclear, however, and the quality of the evidence for its use in this setting was regarded as only "moderate" in the most recent (2008) Society for Nuclear Medicine (SNM) guidelines [3]. An increasing body of data is, however, accumulating to support the suggestion that PET may provide valuable predictive prognostic information, and could usefully contribute to the preoperative decision-making process. The study by Vinh-Hung et al. in a recent issue of European Journal of Nuclear Medicine and Molecular Imaging examines this potential role for PET, and suggests that the identification by PET of positive axillary nodes is predictive of nodal involvement and represents a useful tool for treatment decision making which can reduce the need for sentinel lymph node biopsy (SLNB) [8].

The potential role of PET in preoperative staging in breast carcinoma has been considered in detail by two large systematic reviews which analysed a total of 10 studies of between 18 and 167 patients $[9,10]$. These reviews were examined by a multidisciplinary expert panel under the auspices of the SNM to develop recommendations on the role of PET in oncology [3]. Their analysis showed that if axillary lymph node dissection (ALND) is used as the reference standard, PET demonstrates a sensitivity of 40$93 \%$ and a specificity of $87-100 \%$ in the detection of axillary nodal metastases. If SLNB is used as the reference, PET achieves a sensitivity of $68-96 \%$ and a specificity of $57-80 \%$ [3]. PET accuracy is lower when evaluated against 
both ALND and SNB. The conclusion of the SNM panel was that the technique is insufficiently sensitive in detecting involved axillary lymph nodes, leading to the possibility of false understaging in patients with earlier stage cancer. This is due in part to the limit of resolution of PET/CT being around $3 \mathrm{~mm}$, so that micrometastases (less than $2 \mathrm{~mm}$ ) are not detectable and the smallest axillary node identified in one recent study of the technology was $3 \mathrm{~mm}$ [11]. Extensively necrotic metastases also show less avidity for FDG and may not be identified as a result. Although most of these earlier studies employed stand-alone PET scanners, and therefore did not reflect the improved diagnostic performance of PET/CT, more recent studies using PET/CT still achieved only a relatively poor sensitivity of $58-70 \%$, although specificity was good at $92 \%-100 \%[5,11]$. Given that PET positivity has a high positive predictive value for nodal involvement, it has been suggested by Aukema et al. [12] and corroborated by Vinh-Hung et al. [8], that preoperative PET may represent a useful stratification tool, obviating the need for SLNB in PET-positive patients, so that ALND can be proceeded to immediately. Although at present PET does not normally form part of breast cancer staging, it is sometimes performed as a baseline study for monitoring of response to neoadjuvant therapy, and this could be taken advantage of to reduce the need for SLNB [12]. This could help avoid the necessity for two operative procedures in these patients.

It is recognized that the sensitivity of ${ }^{18} \mathrm{~F}$ FDG PET/CT for detecting the primary tumour in breast carcinoma is relatively low, only around $64 \%$ [13], so that conventional imaging is clearly better suited to this purpose. PET findings may, however, offer useful information on an individual breast carcinoma tumour's biological behaviour. In a recent study of 203 patients with stage cT1-T3,N0 breast carcinoma, FDG uptake as measured by SUV was significantly related to the size of the primary tumour, the number of involved axillary nodes, tumour grade, negative oestrogen receptor (ER) status, high proliferative index and HER2 overexpression. No distant metastases or deaths were seen in the PET-negative patient group. However, SUV was not found to be an independent prognostic factor. The PETnegative and PET-positive groups had 5-year overall survival rates of $100 \%$ and $93 \%$, respectively [14]. In keeping with these findings, triple-negative (negative for ER, progesterone receptor and HER2) breast tumours have been shown to be associated with enhanced FDG uptake [15]. ${ }^{18} \mathrm{~F}-\mathrm{FDG}$ PET/CT could therefore be a useful tool to predict biological characteristics prior to therapy, although the available therapeutic options are not yet sufficiently nuanced or targeted to enable maximal clinical advantage to be taken of this phenotypic variability.

Angiogenesis is an independent strong prognostic factor in breast carcinoma and trials to define the role of targeted therapy with bevacizumab and other tyrosine kinase inhibitors in different settings of the disease are ongoing [16]. Direct PET imaging of angiogenesis in breast cancer is a technique still under development $[17,18]$. However, ${ }^{18} \mathrm{~F}$ FDG PET/CT may offer a more convenient surrogate assay of angiogenetic activity at the present time. It is now recognized that induction of tumour angiogenesis is closely interlinked with the glycolytic pathway via hypoxia-inducible factor 1 (HIF-1), and a recent prospective study has shown that ${ }^{18} \mathrm{~F}$-FDG uptake in breast carcinoma as quantified by SUV is very significantly associated with angiogenesis as evaluated by immunohistochemistry for the endothelial marker CD105 [19]. A positive relationship between tumour metabolism and vascularity has also been shown by studies using ${ }^{15} \mathrm{O}-\mathrm{H}_{2} \mathrm{O}$ PET [20] and MRI [21], and tumour perfusion normalized to cardiac output was significantly correlated with SUV in a study using combined ${ }^{18} \mathrm{~F}$-FDG PET/ dynamic contrast-enhanced CT [22].

The development of new radiotracers is likely to greatly augment the present role of PET by uncovering currently inaccessible information on the biology of individual tumours. PET using the ER imaging agent ${ }^{18} \mathrm{~F}-16 \alpha-17 \beta$ fluoroestradiol is in research use to provide information on ER status of tumours, and appears to be predictive of clinical response to endocrine therapy in ER-positive breast carcinoma [23]. A dedicated breast PET/CT scanner capable of higher spatial resolution than whole-body (WB) PET/CT is in development, and early results show much improved performance compared to WB PET/CT. For example, a sensitivity of $91 \%$ has been reported for the detection of ductal carcinoma in situ compared to only $25 \%$ using WB PET [24]. The small size of these scanners would enable their use in breast imaging clinics, with direct correlation of the findings with mammographic appearances.

In summary, although approval for a routine role for preoperative PET in breast carcinoma may yet require further supportive evidence, the potential is clearly there to add a new dimension to the noninvasive evaluation of patients with the disease, and reveal new biological information to facilitate selection of the best possible therapy.

\section{References}

1. Syed R, Bomanji J, Nagabushan N, Hughes S, Kayani I, Groves $\mathrm{AM}$, et al. Impact of combined FDG PET on the management of head and neck tumour. Br J Cancer. 2005;92:1046-50.

2. Goh V, Engeldow A, Rodriguez-Justo M, Shastry M, Blackman G, Endozo R, et al. Assessment of primary colorectal cancer by integrated 18F-FDG PET/perfusion CT: decoupling of flow and metabolism occurs in early not late stage cancer. J Nucl Med. 2012;53:687-92.

3. Fletcher JW, Djulbegovic B, Soares HP, Siegel BA, Lowe VJ, Lyman GH, et al. Recommendations on the use of $18 \mathrm{~F}-\mathrm{FDG}$ PET in oncology. J Nucl Med. 2008;49:480-508. 
4. Rosen EL, Eubank WB, Mankoff DA. FDG PET, PET/CT, and breast cancer imaging. Radiographics. 2007;27:S215-29.

5. Fuster D, Duch J, Paredes P, Velasco M, Muñoz M, Santamaría G, et al. Preoperative staging of large primary breast cancer with $[18 \mathrm{~F}]$ fluorodeoxyglucose positron emission tomography/computed tomography compared with conventional imaging procedures. J Clin Oncol. 2008;26:4746-51.

6. Bernsdorf M, Berthelsen AK, Wielenga VT, Kroman N, Teilum D, Binderup T, et al. Preoperative PET/CT in early-stage breast cancer. Ann Oncol. 2012;23:2277-82.

7. Groves AM, Shastry M, Ben-Haim S, Kayani I, Malhotra A, Davidson T, et al. Defining the role of PET-CT in staging early breast cancer. Oncologist. 2012;17:613-9

8. Vinh-Hung V, Everaert H, Lamote J, Voordeckers M, van Parijs H, Vanhoeij M, et al. Diagnostic and prognostic correlates of preoperative FDG PET for breast cancer. Eur J Nucl Med Mol Imaging. 2012;39:1618-1627.

9. Facey K, Bradbury I, Laking G, Payne E. Overview of the clinical effectiveness of positron emission tomography imaging in selected cancers. Health Technol Assess. 2007;11:iii-iv. xi-267.

10. Blue Cross and Blue Shield Association. FDG positron emission tomography for evaluating breast cancer. TEC Bull (Online). 2003;20:1-7.

11. Heusner TA, Kuemmel S, Hahn S, Koeninger A, Otterbach F, Hamami ME, et al. Diagnostic value of full-dose FDG PET/CT for axillary lymph node staging in breast cancer patients. Eur J Nucl Med Mol Imaging. 2009;36:1543-50.

12. Aukema TS, Straver ME, Valdés Olmos RA, Vogel WV. A different role for FDG PET/CT in axillary lymph node staging in breast cancer. Eur J Nucl Med Mol Imaging. 2009;36:1896-7. Author reply 1898-99.

13. Avril N, Rosé CA, Schelling M, Dose J, Kuhn W, Bense S, et al. Breast imaging with positron emission tomography and fluorine18 fluorodeoxyglucose: use and limitations. J Clin Oncol. 2000; 18:3495-502.

14. De Cicco C, Gilardi L, Botteri E, Fracassi SL, Di Dia GA, Botta F, et al. Is [(18)F] fluorodeoxyglucose uptake by the primary tumor a prognostic factor in breast cancer? Breast. 2012. doi:10.1016/ j.breast.2012.05.009.
15. Basu S, Chen W, Tchou J, Mavi A, Cermik T, Czerniecki B, et al. Comparison of triple-negative and estrogen receptor-positive/progesterone receptor-positive/HER2-negative breast carcinoma using quantitative fluorine-18 fluorodeoxyglucose/positron emission tomography imaging parameters: a potentially useful method for disease characterization. Cancer. 2008;112:995-1000.

16. Bareschino MA, Schettino C, Colantuoni G, Rossi E, Rossi A, Maione $\mathrm{P}$, et al. The role of antiangiogenetic agents in the treatment of breast cancer. Curr Med Chem. 2011;18:5022-32.

17. Hong H, Yang Y, Zhang Y, Engle JW, Barnhart TE, Nickles RJ, et al. Positron emission tomography imaging of CD105 expression during tumor angiogenesis. Eur J Nucl Med Mol Imaging. 2011; $38: 1335-43$.

18. Liu Z, Liu S, Wang F, Liu S, Chen X. Noninvasive imaging of tumor integrin expression using (18)F-labeled RGD dimer peptide with PEG (4) linkers. Eur J Nucl Med Mol Imaging. 2009; 36:1296-307.

19. Groves AM, Shastry M, Rodriguez-Justo M, Malhotra A, Endozo R, Davidson T, et al. 18F-FDG PET and biomarkers for tumour angiogenesis in early breast cancer. Eur J Nucl Med Mol Imaging. 2011;38:46-52.

20. Mankoff DA, Dunnwald LK, Gralow JR, Ellis GK, Charlop A, Lawton TJ, Schubert EK, et al. Blood flow and metabolism in locally advanced breast cancer: relationship to response to therapy. J Nucl Med. 2002;43:500-9.

21. Semple SIK, Gilbert FJ, Redpath TW, Staff RT, Ahearn TS, Welch $\mathrm{AE}$, et al. The relationship between vascular and metabolic characteristics of primary breast tumours. Eur Radiol. 2004;14:203845.

22. Groves AM, Wishart GC, Shastry M, Moyle P, Iddles S, Britton P, et al. Metabolic-flow relationships in primary breast cancer: feasibility of combined PET/dynamic contrast-enhanced CT. Eur J Nucl Med Mol Imaging. 2009;36:416-21.

23. Cochet A, Generali D, Fox SB, Ferrozzi F, Hicks RJ. Positron emission tomography and neoadjuvant therapy of breast cancer. J Natl Cancer Inst Monogr. 2011;2011:111-5.

24. Hodgson NC, Gulenchyn KY. Is there a role for positron emission tomography in breast cancer staging? J Clin Oncol. 2008;26:712-20. 